REVISTA DE URBANISMO

$\mathrm{N}^{\circ}$ 21, diciembre de 2009

ISSN 0717-5051

\title{
Aproximación a una formulación de los Derechos Urbanos - Chile
}

\author{
Henríquez Orellana, Patricia - Dinamarca Silva, Cecilia \\ M. Patricia Henríquez Orellana, Arqta. U. Chile, Profesora Asistente, \\ Investigadora en el Departamento de Urbanismo de la Facultad de Arquitectura y \\ Urbanismo de la Universidad de Chile, Directora del Comité de Derechos \\ Humanos y Ciudadanos del Colegio de Arquitectos de Chile. \\ Cecilia Dinamarca Silva, Arqta. U. de Chile, Magister en Urbanismo Universidad \\ Nacional Autónoma México, Presidenta del Comité de Derechos Humanos y \\ Ciudadanos del Colegio de Arquitectos de Chile.

$$
\begin{aligned}
& \text { E-mail: } \\
& ::>\text { Resumen } \\
& \text { ::> Introducción } \\
& \text { ::> Enunciado de algunos derechos urbanos } \\
& \text { :i> Conclusiones } \\
& ::>\text { Bibliografía } \\
& ::>\text { Versión completa/Complete version }
\end{aligned}
$$

Palabras Claves: DERECHOS HUMANOS. DERECHOS URBANOS. CARTA DERECHOS URBANOS. HUMAN RIGHTS, URBAN RIGHTS, LETTER URBAN RIGHTS.

\section{Citación:}

Henríquez Orellana, Patricia; Dinamarca Silva, Cecilia. Aproximación a una formación de los Derechos Urbanos-Chile. En: Revista de Urbanismo, №21, Santiago de Chile, publicación electrónica editada por el Departamento de Urbanismo, F.A.U. de la Universidad de Chile, diciembre de 2009, I.S.S.N. 07175051.http://revistaurbanismo.uchile.cl/CDA/urb completa/urb21 Henriquez 001. $\underline{\mathrm{html}}$ 


\section{Resumen}

Se intenta enunciar los "derechos urbanos", desde la perspectiva de la Comisión de Derechos Humanos y Ciudadanos del Colegio de Arquitectos.

\section{Abstract}

It tries to enunciate the "urban rights" from the perspective of the Commission on Human Rights and Citizens Association of Architects.

"Toda persona tiene derecho a un nivel de vida adecuado que le asegure, así como a su familia, la salud y el bienestar, y en especial la alimentación, el vestido, la vivienda, la asistencia médica y los servicios sociales necesarios...".

Artículo 25, No 1 de la Declaración Universal de Derechos Humanos, adoptada y proclamada el 10 de diciembre de 1948 por las Naciones Unidas y suscrita por Chile.

"El derecho a la ciudad es interligado e interdependiente a todos los $D D H H$ internacionalmente reconocidos concebidos integralmente, luego, incluye el derecho a la tierra, a los medios de subsistencia, al trabajo, a la salud, educación, cultura, habitación, protección social, seguridad, medio ambiente sano, saneamiento, transporte público, entretenimiento e información..."

Propuesta Carta Mundial por el Derecho a la Ciudad. II Foro Social Mundial, Porto Alegre 2002.

\section{Introducción}

La Declaración Universal de Derechos Humanos es uno de los documentos más importantes del siglo XX y una referencia central para quienes trabajan por el bienestar humano y la ciudadanía. Los Derechos Humanos, es un tema que se ha instalado en todas las esferas de la sociedad y su importancia es creciente en la medida que las sociedades aumentan su nivel de desarrollo y cultura. En este contexto se incluyen también los derechos ciudadanos y urbanos, como bien lo expresa la propuesta de la Carta Mundial por el Derecho a la Ciudad suscrita por distintas organizaciones y movimientos sociales de todo el mundo[1].

En el ámbito de los Derechos Urbanos aumentan progresivamente las organizaciones ciudadanas que defienden sus derechos ante la prevaricación urbanística y se enfrentan a proyectos públicos y privados con malas soluciones técnicas y con fuertes impactos negativos sobre la ciudad y sus habitantes.

Estas organizaciones se ven obligadas a opinar y defenderse en temas que tienen que ver con la aplicación, u omisión, de políticas y normativa urbana y 
arquitectónica que atentan contra los derechos ciudadanos, rol que deberían desempeñar naturalmente los arquitectos y urbanistas muy activamente desde el Colegio de Arquitectos. Colegio cuya vigencia, por lo demás, está estrechamente unida a que desempeñe un rol representativo del interés público o colectivo -en aquellos temas relativos a la profesión- afectado por irregularidades conocidas ampliamente por la ciudadanía.

El ejercicio de una ciudadanía plena requiere igualdad de derechos para todos los ciudadanos, sin discriminación de edad, clase, género, etnia, orientación sexual, religión, política, discapacidad física, condición migratoria, o de cualquier tipo.

La tolerancia urbana debe ser activa: significa la apertura al mundo de los otros, percibiendo las diferencias como enriquecimiento, mirando y tratando a los otros como iguales con idénticos derechos.

La ciudad no significa la uniformidad o la homogeneización, los individuos, los grupos, las comunidades, las organizaciones políticas, las culturas desean ser y deben seguir siendo diversos o únicos. Los guetos espaciales, los barrios segregados, se deben sustituir por vínculos urbanos, por espacios de interacción que produzcan habitantes con mentalidad ciudadana profundamente humana e integradora, pero también por vecindades, barrios, calles, espacios públicos con identidad.

La potencialidad de la ciudad indica la calidad de vida de sus habitantes y esto se refleja en los países tercermundistas donde la concentración de la riqueza y el poder que generan pobreza y exclusión contribuyen a la depredación del ambiente y aceleran los procesos migratorios y de urbanización, la segregación social y espacial y la privatización de los bienes comunes y del espacio público.

Estos procesos favorecen la proliferación de grandes áreas urbanas en condiciones de pobreza, precariedad y vulnerabilidad.

\section{Nota}

[1] El Seminario Mundial por el Derecho a la Ciudad - Contra la Desigualdad y la Discriminación, realizado durante el Foro, tuvo como objetivo establecer un proceso amplio y democrático para lograr la elaboración de la Carta Mundial de los Derechos Humanos en la Ciudad. Fuente: www.forumsocialmundial.org.br

\section{Enunciado de algunos derechos urbanos}

Todas las personas sin exclusión, tienen derecho a la ciudad, a vivir en ella, esto significa, entender la ciudad como espacio colectivo que pertenece a todos sus habitantes, donde el Estado garantice las condiciones para la óptima calidad de 
vida, traducida en, al menos, los siguientes derechos:
a)
Derecho
al
lugar
y
a
la
permanencia

Todas las personas que viven en un lugar que han contribuido a construir, en el que están arraigadas y que proporciona sentido a su vida, deben poder continuar viviendo en él (en su vecindad, barrio o comuna) y tienen derecho a la reubicación en la misma área si ésta se transforma por proyectos inmobiliarios, políticas de desarrollo urbano, megaproyectos de infraestructura u otros.

El Estado protegerá a las poblaciones vulnerables que puedan sufrir procesos de expulsión o de impactos negativos (acústicos, visuales, barreras espaciales, etc.) por parte de proyectos tanto del sector público como del sector privado.

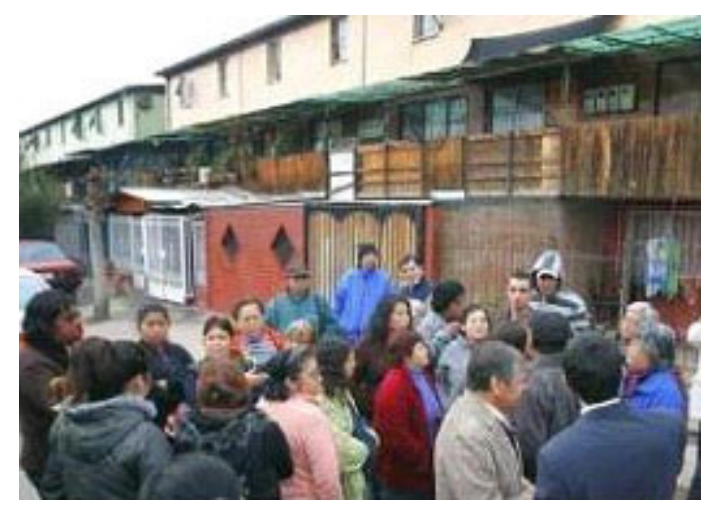

Fig. 1. Comuna de Cerro Navia, proceso de erradicación total o parcial de los habitantes, por deterioro de las viviendas. Villa Las Viñitas, conjunto de 1.318 viviendas sociales. Vecinos demandan la reconstrucción en el mismo terreno.

Fuente: http//mapadeconflictos. sitiosur.cl

\section{b) Derecho a la vivienda}

Todos los ciudadanos tienen derecho a una vivienda digna, segura y salubre, donde puedan habitar plenamente. Esto último significa que la vivienda será más que un "dormidero", en ella debe ser posible la creatividad doméstica. El Estado debe asegurar una oferta adecuada de vivienda y de equipamiento y espacios públicos de vecindad y de barrio, poniendo los medios y estableciendo los apoyos necesarios para que todos los habitantes puedan hacerlo efectivo, proporcionando asistencia técnica e información suficiente y oportuna sobre planes y programas. Para la vivienda debe proveer los servicios de infraestructura básicos (luz, agua, 
alcantarillado, vialidad).

Los sin casa, sean allegados, población transitoria, población ambulatoria, migrantes y refugiados, tienen derecho a permanecer en la ciudad en condiciones compatibles con la dignidad humana, previendo el Estado las situaciones que pudieran derivar de eventos catastróficos. La ciudad debe contar con albergues y viviendas sociales para refugiados víctimas de cualquier tipo de violencia, nómades urbanos, o en cualquier condición de abandono o vulnerabilidad.

Los habitantes tienen derecho a contar con lugares centrales con equipamientos y servicios, accesibles a todos, tanto física como socialmente.

\section{c) Derecho a la movilidad y a la accesibilidad urbana}

La movilidad es indispensable desde un punto de vista económico y social, es una condición clave de acceso al trabajo, a la vivienda a la educación, a la cultura y el ocio, a la familia, a la multiplicidad de la oferta urbana.

Todos los habitantes de la ciudad deben tener iguales posibilidades de acceso a los centros o subcentros de la ciudad y a la comuna histórica y central, dónde se concentran los servicios y el equipamiento principal. Cada parte de la ciudad debe ser accesible y visible para todos sus habitantes. Debe contar con elementos que permitan el desplazamiento seguro de las personas de movilidad reducida.

El derecho a moverse con facilidad por la ciudad debe universalizarse, la movilidad desde cada zona de la ciudad debe ser igualitaria y no reservarse sólo a los que disponen de un vehículo.

La autonomía de las personas - de diferentes grupos de edad, género, condición física- requiere una oferta multimodal amplia, compleja y diversificada. El Estado debe proporcionar un sistema de transporte público accesible, a precio razonable, seguro, diverso y adecuado a las diferentes necesidades ambientales y sociales. Privilegiando el tránsito de los peatones, estimulando la peatonalización en la ciudad.
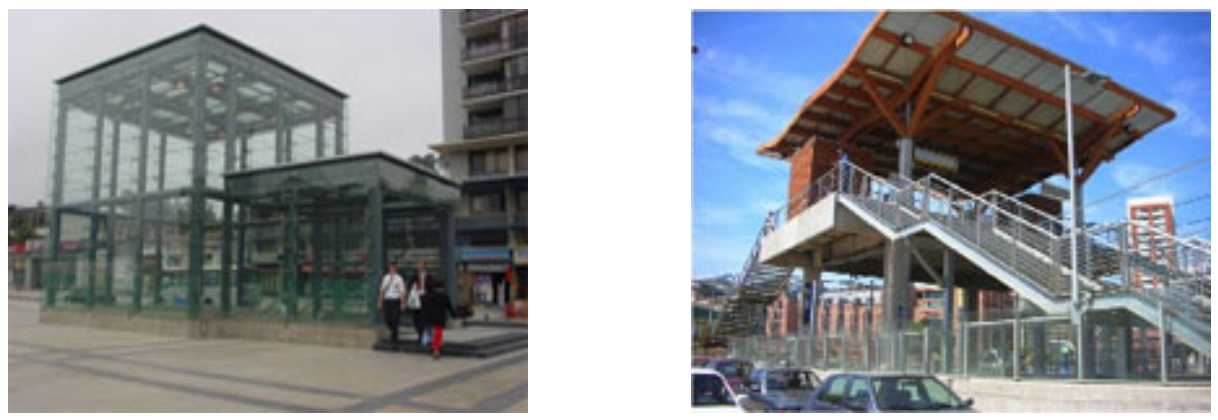

Fig. 2. (foto izq.) Viña del Mar, Fig. 3. (foto der.) Valparaíso, estación metro tren: accesibilidad estación metro tren: accesibilidad 
universal. Foto $\mathrm{PHO}$.

inadecuada para personas de

movilidad reducida debido a

escaleras, duplicación de los

recorridos y falta de protección del exterior. Foto $\mathrm{PHO}$.

\section{d) Derecho a disponer de espacios públicos y equipamiento}

El espacio público -calles, plazas, parques, paseos, incluyendo los bordes de mar (Valparaíso, Puerto Montt) o de ríos (Valdivia, Concepción), la cordillera y su pie de monte (Santiago)- es una de las condiciones básicas para la justicia urbana, un factor de redistribución social, un ordenador de la ciudad igualitaria e integradora. El Estado debe garantizar los espacios públicos para la convivencia pacífica, el desarrollo colectivo, las manifestaciones ciudadanas y el ejercicio de la solidaridad. La seguridad urbana debe ser un atributo del espacio público, deben diseñarse "protectores", es decir, por sobre toda otra medida, "animados".

Los espacios públicos, como los parques, deben contar con el equipamiento de alta calidad para el ocio, actividades físicas y deportivas.

Todas las zonas de la ciudad deben estar articuladas por un sistema de espacios públicos plenamente accesibles y diversificados.

El Estado debe garantizar la protección de los espacios públicos de la apropiación indebida que efectúan tanto privados como organismos públicos (comercio, inmobiliarias, municipios).
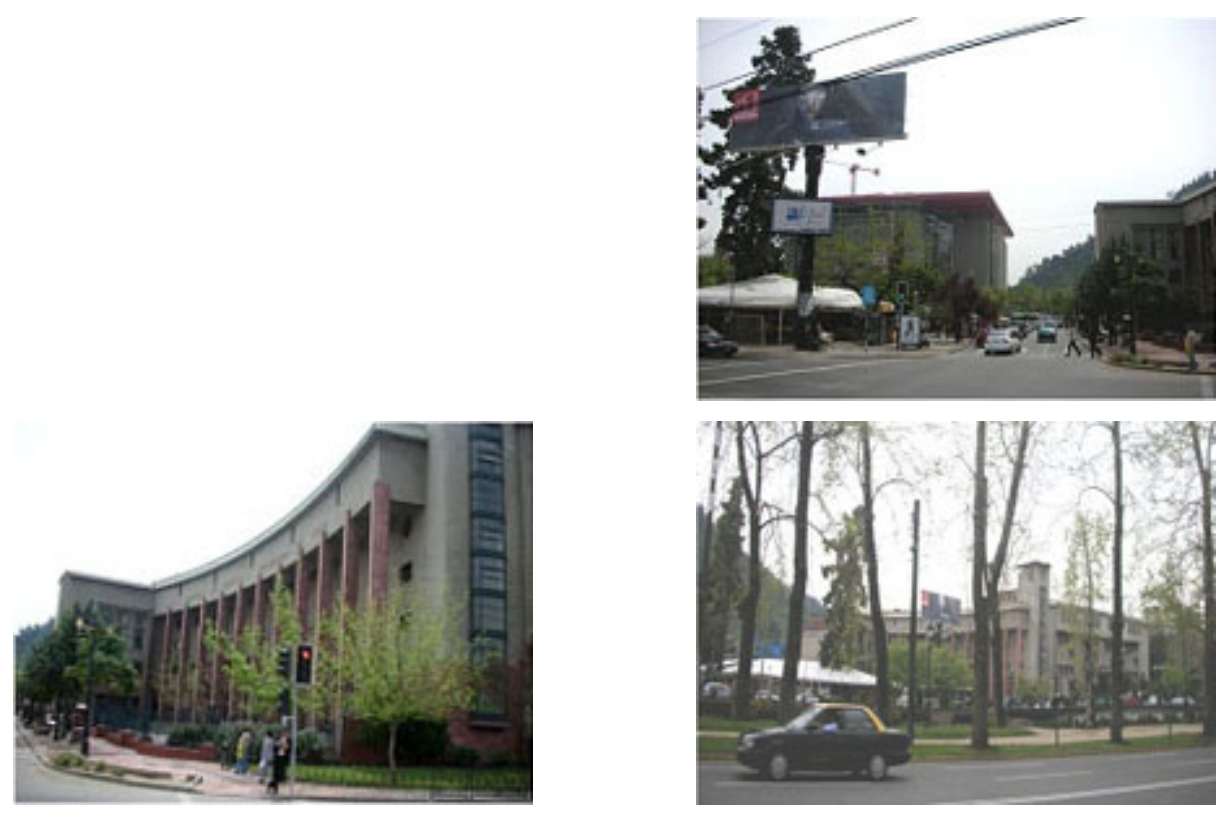
Fig. 4, 5, 6 y 7. Plaza José Domingo Gómez Rojas y edificio patrimonial Escuela de Derecho del arqto. Juan Martínez. Pérdida del principal espacio público tradicional de Santiago, invadido por ocupación comercial, paletas publicitarias monumentales y nueva edificación en el entorno (fotos PHO y CDS).
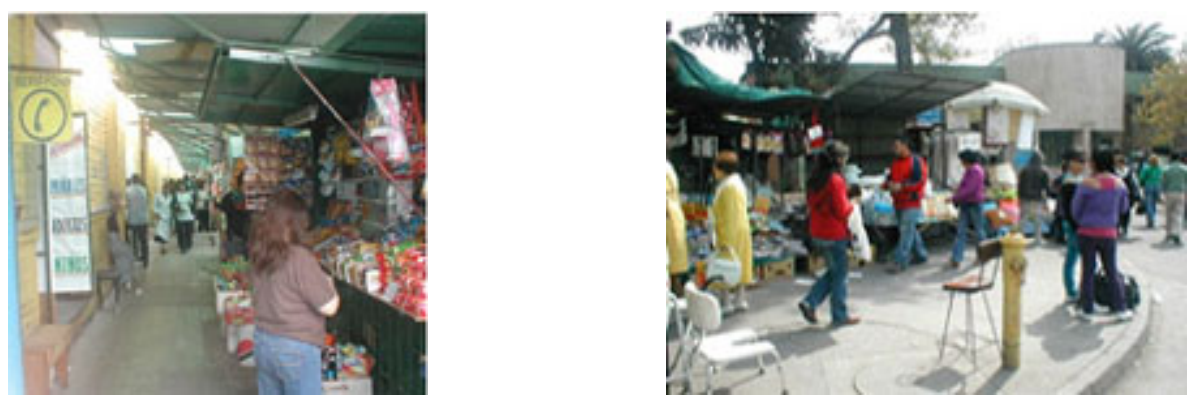

Fig. 8. y Fig. 9. Comuna de Independencia, Santiago. Ocupación indebida del espacio público de la calle: Vereda norte de calle Zañartu en el acceso a Hospitales del área norte metropolitana (foto CDS).

\section{e) Derecho a la diversidad}

Las vecindades, barrios y comunas de la ciudad deben tener la diversidad y mixtura social, de usos y actividades que enriquezcan la vida ciudadana, evitando la segregación social y económica.
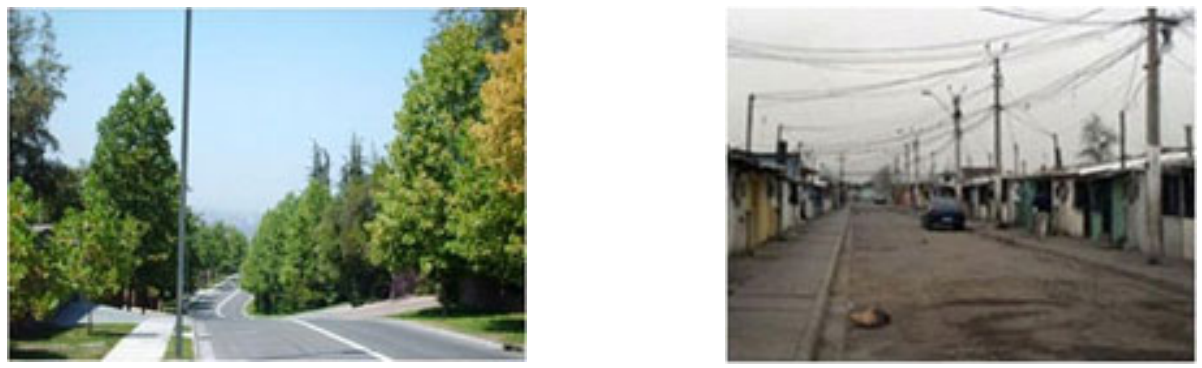

Fig. 10 y Fig. 11. Segregación social y económica de distinto signo, empobrecimiento de la diversidad de la vida urbana: Calle La Dehesa versus calle población La Legua.

\section{f) Derecho a preservar la memoria y la identidad cultural}

Derecho a la identidad colectiva, donde la organización interna del espacio urbano debe facilitar la cohesión sociocultural de las comunidades ya sea de barrio, grupos de edad, grupos étnicos, deportivos, etc.

La preservación del patrimonio arquitectónico y urbano es parte de la identidad de la ciudad y sus habitantes. La ciudad contiene la memoria colectiva, y el habitante tiene derecho a "reconocerse" en el lugar donde habita. 


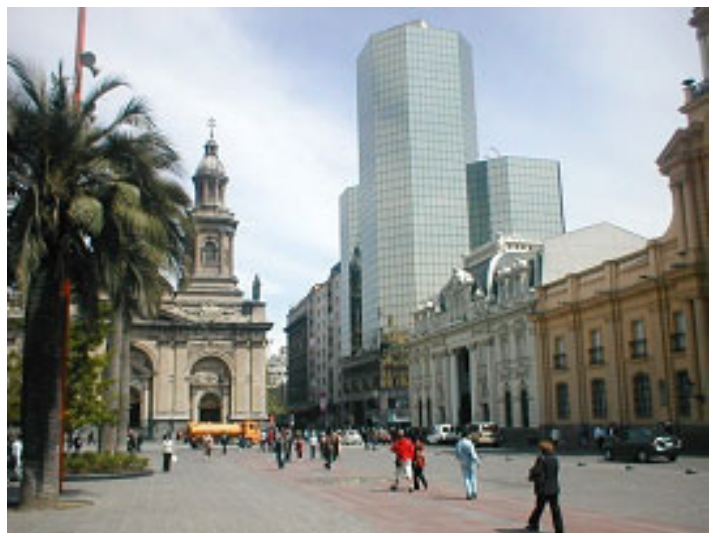

Fig. 12. PLAZA DE ARMAS, SANTIAGO.

Torre de cristal: Intervención y distorsión del espacio público patrimonial (Foto CDS).

\section{g) Derecho a la belleza y armonía}

La belleza y la calidad del espacio público y de los equipamientos colectivos es justicia redistributiva. Los programas públicos de vivienda, infraestructura y servicios deben incorporar la dimensión estética, el buen diseño, como prueba de calidad urbana y de reconocimiento cívico.

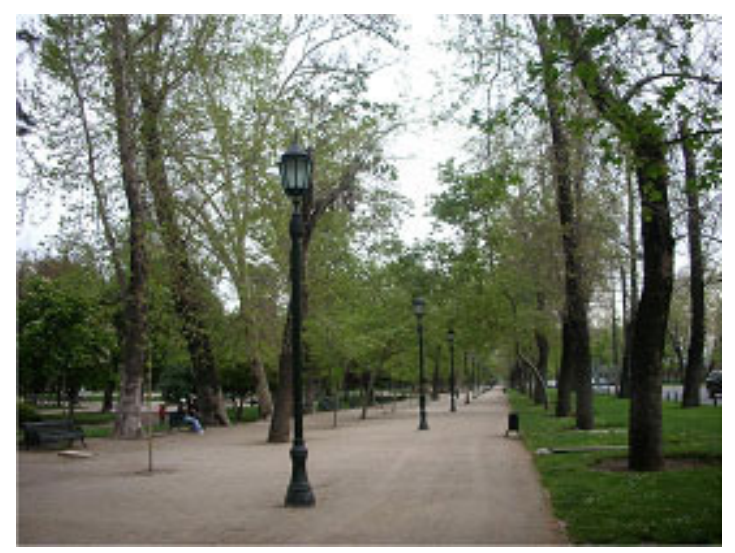

Fig. 13. Comuna de Santiago, Parque Forestal. Belleza y calidad del parque urbano (foto PHO). 

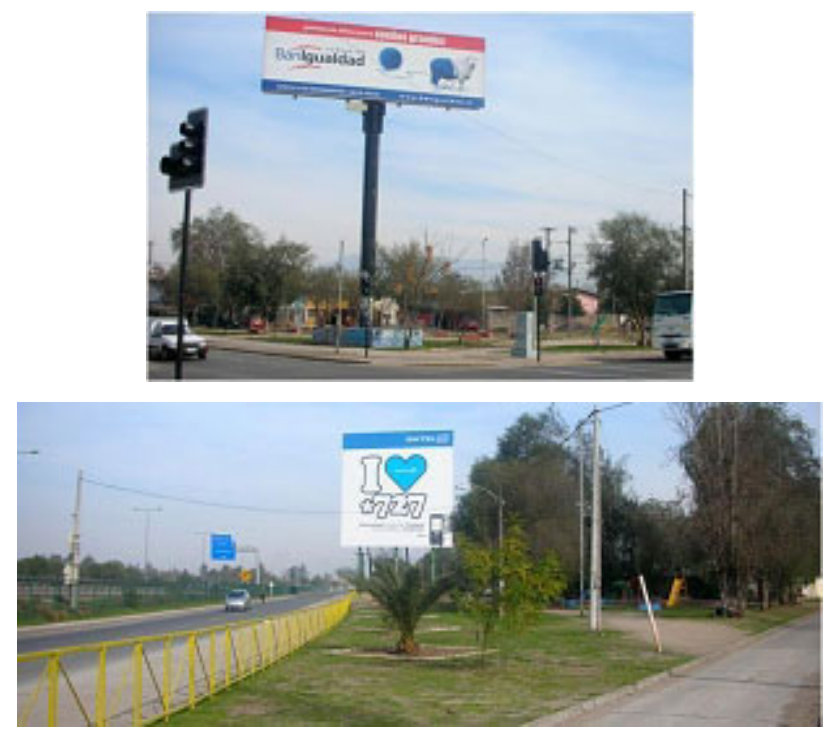

Fig. 14 y Fig. 15. Comuna Renca, plazuelas de la calle local Costanera Norte: Fealdad y deterioro del espacio público por la instalación de propaganda monumental (fotos $\mathrm{PHO}$ ).

\section{h) Derecho a vivir en un medio ambiente libre de contaminación[2]}

Los ciudadanos tienen derecho a un medio ambiente sano que compatibilice el desarrollo económico y el equilibrio ambiental. El Estado debe garantizar este derecho adoptando políticas de prevención de la contaminación de todo tipo y de la ocupación desordenada del territorio.

El Estado debe tener a su cargo y garantizar la limpieza de la ciudad y la recolección, tratamiento y reciclaje de los residuos domiciliarios y urbanos en general.

El Estado debe desarrollar una educación orientada al respeto a la naturaleza. Deberá poner en práctica las acciones necesarias para que los ciudadanos puedan apreciar el paisaje que rodea y configura la ciudad y sean consultados sobre las modificaciones que puedan alterarlo. 


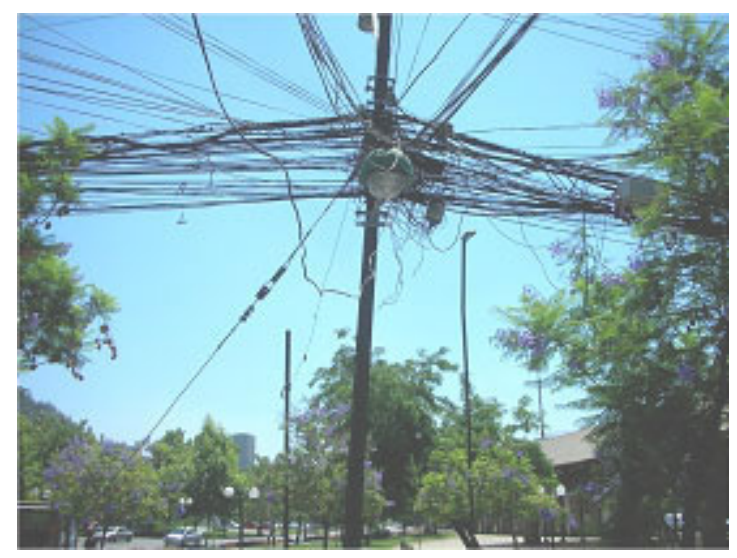

Fig. 16. ¿Quién es responsable?... contaminación visual Barrio Bellavista, comuna de Providencia.
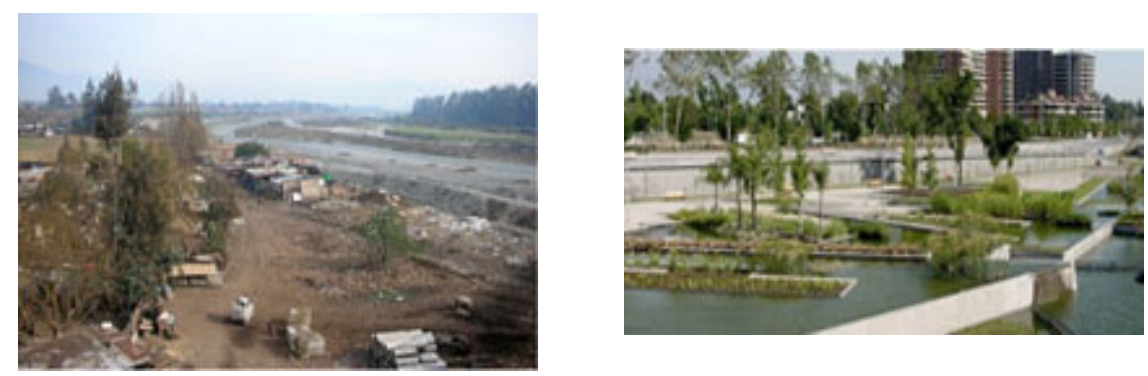

Fig. 17. - y fig. 18.- Río Mapocho: Espacio de la ribera del río. Comuna de Peñaflor, contaminación antrópica de la ribera del río (foto izq.), versus comuna de Vitacura, tratamiento de nuevo Parque Bicentenario, área verde con una superficie de 30 hectáreas, entre la rotonda Pérez Zujovic, la Av. Bicentenario, y la futura Costanera Sur, lo que es actualmente ribera del río Mapocho (foto der.).

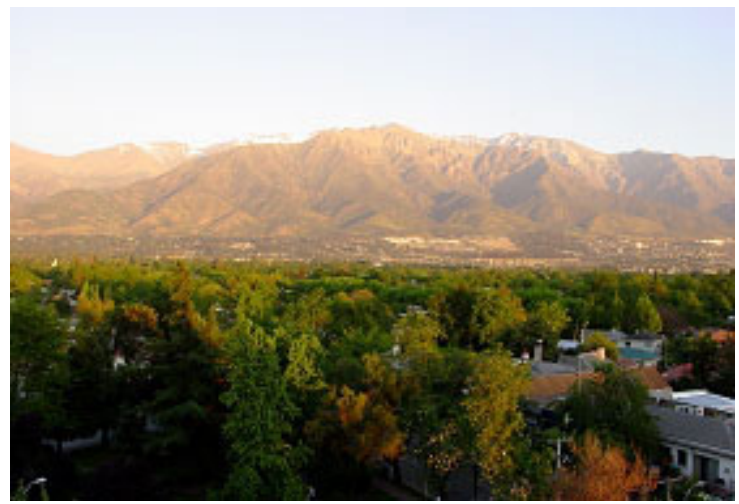


Fig. 19. Vista de la cordillera sin polución atmosférica: Comuna de La Reina y pie de monte comuna de Peñalolén (foto PHO).

\section{i) Derecho a la participación ciudadana}

Las decisiones públicas sobre la ciudad deben consultarse con los habitantes, usuarios, actores sociales y expertos de todas las disciplinas. El Estado debe establecer los mecanismos para un proceso de participación democrático y vinculante, en todas las etapas de un proyecto urbano, desde la idea inicial y el proyecto, la construcción, hasta finalmente durante su operación; o en la etapa de explotación si se trata de proyectos administrados por concesiones a privados como son las autopistas urbanas, aeropuertos, infraestructura del transporte público, u otros.

El Estado debe estimular y respaldar activamente los procesos de iniciativa popular en la propuesta de proyectos de ley y planes de desarrollo urbano y en las acciones autogestionarias de mejoramiento del hábitat y la vivienda.
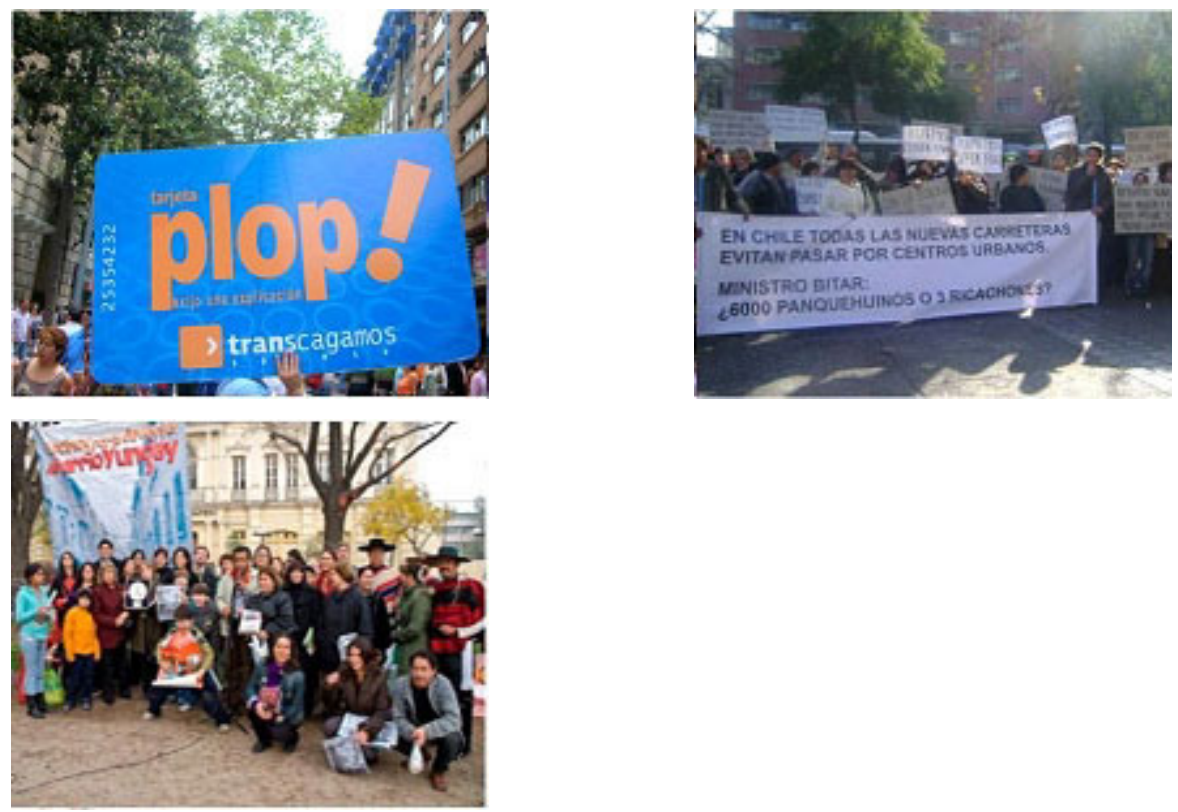

Figs. 20,21,22. Manifestaciones ciudadanas (foto $20 \mathrm{PHO}$, y otras fotos de www.plataformaurbana.cl).

\section{Nota}

[2] Constitución Política de Chile, Derechos y Deberes, artículo 8: "El derecho a vivir en un ambiente libre de contaminación. Es deber del 
Estado velar para que este derecho no sea afectado y tutelar la preservación de la naturaleza".

\section{Conclusiones}

\section{Formular las políticas que busquen respuesta a los problemas de la ciudad}

Muchos de los derechos que se ha detallado y enunciado tentativamente, en realidad corresponden a un derecho fundamental de todo ser humano y colectividad, que es el derecho a "contar con un Plan".[3] Tal como un padre y/o una madre tienen derecho a tener hijos, y también a contar con un plan para su crecimiento y desarrollo, para que lleguen a adultos en forma adecuada, también los habitantes de una ciudad tienen derecho a la ciudad y a contar con un plan integral de desarrollo urbano, no sólo normativo.

Parece necesario prever los tipos de intervenciones mayores según sea la realidad de la ciudad más allá de su normalidad. En el caso de las ciudades ubicadas sobre la cornisa andina, en permanente movimiento, no es aceptable esperar que ocurra el terremoto para pensar cómo se actúa y qué prioridades se debe atender conforme a ningún ordenamiento territorial ni visión de futuro, como suele ocurrir.

\section{Crear la institucionalidad necesaria}

Sistemas de normas sobre la base de los Derechos Urbanos deben diseñarse entendiendo que no es posible que en un contexto de adelgazamiento del Estado este termine casi renunciando a sus funciones primordiales, como ocurre en Chile, sino que es necesario reforzar justamente sus atribuciones a las cuales no deberá renunciar, pues ese sería el comienzo de su propia desintegración.

\section{Educación}

La enseñanza del Urbanismo, sus principios, debería incorporarse en las asignaturas de la enseñanza media. En la Universidad por otra parte, la enseñanza debe contemplar contenidos y objetivos asociados a los Derechos Urbanos, más que a la legislación urbana.

\section{Colegio de Arquitectos al Siglo XXI}

Finalmente planteamos que formular la "Carta de Derechos Urbanos" para la realidad chilena del siglo XXI, logrando su promulgación vinculante con la Constitución Política de Chile es una tarea que el Colegio de Arquitectos debe iniciar hoy.

\section{Nota}


[3] Véase Pavez R., M.I., 2007 op Cit., y también Gurovich, A.; Calderón, E.Pavez, M.I. 1994 op Cit.

\section{Bibliografía}

- ASCHER, Francois (2004): "Los Nuevos Principios del Urbanismo". Ed. cast. Alianza Editorial, S.A. Madrid.

- BORJA, Jordi (2005): “Un Futuro con un Corazón Antiguo" Revista Bibliográfica de Geografía y Ciencias Sociales. Universidad de Barcelona. Mayo 2005.

- BORJA, Jordi; MUXI, Zaida (2003): "El Espacio Público: Ciudad y Ciudadanía", Ediciones Electa, Barcelona.

- CEPAL (2004): "Carta por el Derecho de las Mujeres a la Ciudad", México.

- GUROVICH, A.; CALDERÓN, E.; PAVEZ, M.I. (1994), “¿Hacia el no-plan de la no-ciudad?", en REVISTA De Arquitectura N ${ }^{\circ} 5$, Santiago, ISSN 0716-8772, Ed. F.A.U.- U. Chile, nov. 1994, pp.7-9, ilustradas. [En línea en Revista de Urbanismo Nº1 Especial 'Pensamiento Década 1990', $<$ http://revistaurbanismo.uchile.cl>]

- INSTITUTO DE DERECHOS HUMANOS DE CATALUÑA (2006): Hacia una Carta - Agenda Mundial por los Derechos Humanos en la Ciudad.

- PAVEZ R., M. Isabel (2006): "Identidad, ordenamiento territorial y oportunidades: espacios públicos y recreación para la Región Metropolitana de Santiago Siglo XXI", 2006. En: REVISTA DE URBANISMO, digital, N¹4, D. Urbanismo F.A.U. U. de Chile, Primer semestre 2006, 21 págs. ilustradas. URL http://revistaurbanismo.uchile.cl

- Página web: www.forumsocialmundial.org.br

- Página web: http//mapadeconflictos.sitiosur.cl

Nota: Este escrito corresponde a una ponencia presentada al XXI Congreso Nacional de Arquitectos del Colegio de Arquitectos de Chile. Octubre 2009. 